\title{
Examining non-structural retrofitting status of teaching hospitals in Kerman against disasters
}

\author{
Mahmood Nekooi Moghadam ${ }^{1}$, Seyed Mobin Moradi $^{2}$, Mohammadreza Amiresmaili $^{3}$
}

${ }^{1} \mathrm{Ph} . \mathrm{D}$. of Health Services Management, Professor, Modeling in Health Research Center, Institute for Futures Studies in Health, Kerman University of Medical Sciences, Kerman, Iran

${ }^{2} \mathrm{Ph}$.D. Student in Health in Emergency and Disasters, Environmental Health Engineering Research Center, Kerman University of Medical Sciences, Kerman, Iran

${ }^{3} \mathrm{Ph}$.D. of Health Services Management, Associate Professor, Medical Informatics Research Center, Institute for Futures Studies in Health, Kerman University of Medical Sciences, Kerman, Iran

\section{Type of article: Original}

\begin{abstract}
Background and objective: Continuous services provision of a hospital before and after a disaster is one of the most prominent issues that all people, especially the authorities must take into huge consideration. Concerning the experiences of previous earthquakes, the role and importance of nonstructural components becomes increasingly clear in the uninterrupted services of hospitals. In this study, non-structural retrofitting status of Kerman teaching hospitals was evaluated against natural disasters.

Methods: This cross-sectional study was carried out in the second half of 2014 on the teaching hospitals in Kerman (Iran). The study population consisted of all Kerman teaching hospitals. The research instrument was World Health Organization/Pan American Health Organization (WHO/PAHO) standard checklist. Data analysis was carried out using descriptive statistics through SPSS 19.

Results: One hospital had a low retrofitting level, two hospitals had an average level and one had a high level. In the examined hospitals in this study, the medical gas section had the lowest preparedness against natural disasters, while the office, warehouse and furniture section had the highest resistance. Generally, the nonstructural retrofitting status was $50 \%$ in one hospital and was between $65 \%$ and $85 \%$ in other hospitals.

Conclusions: Generally, the retrofitting status of hospitals was not at the ideal condition, most hospitals were in average condition. Concerning the high risk of hospitals in disasters, it is necessary that senior executives and managers of Kerman Province and Kerman University of Medical Sciences take some measures to retrofit these buildings and to reduce the risk of vulnerability.
\end{abstract}

Keywords: Retrofitting, Non-structural components, Teaching hospitals

\section{Introduction}

Survival on earth, dealing with natural disasters and protecting life and property against these disasters have been one of the greatest challenges in the history of mankind (1). Nowadays, accidents and disasters account for a large part of the resources and programs of governments. Statistics represent a growing trend of events and accidents all around the world. They impose huge casualties and financial losses on governments and nations every year (2). According to the definition of the Emergency Disasters Data Base (EM-DAT), accidents and disasters are events of which responding to, is beyond the existing capacities; to manage and control them, we need help from a place outside of the disaster-stricken area (3). Iran, a developing country in Asia, is prone to various natural and manmade disasters, and is considered as one of the most vulnerable countries in the world. Health is very important to all sections involved in managing disasters and events, because the first and the most important concerns and demands of people is health (2). Presence of health care centers is one of the basic needs of human societies at all times, but even more so, during natural disasters such as volcanic eruptions, hurricanes, floods and earthquakes.

\section{Corresponding author:}

Seyed Mobin Moradi, Environmental Health Engineering Research Center, Kerman University of Medical Sciences, Kerman, Iran. Tel: +98.9371930275 \&+98.9163992853, Email: mobin_moradi@yahoo.com

Received: May 22, 2016, Accepted: August 07, 2016, Published: May 2017

iThenticate screening: August 02, 2016, English editing: November 22, 2016, Quality control: March 12, 2017

(C) 2017 The Authors. This is an open access article under the terms of the Creative Commons Attribution-NonCommercialNoDerivs License, which permits use and distribution in any medium, provided the original work is properly cited, the use is non-commercial and no modifications or adaptations are made. 
Continuous service provision of a hospital before and after a disaster is one of the most prominent issues that all people, especially the authorities must take into huge consideration. Concerning the experiences of previous earthquakes, the role and importance of nonstructural components becomes increasingly clear in the uninterrupted services of hospitals (4). According to its definition, non-structural components are all elements and contents inside the buildings except for the structural parts including beams, columns, and floors and so on. Non-structural elements are commonly found in ceilings, windows, office supplies, computers, shelves, drawers and objects inside them, emergency power generators, liquid storage tanks, telecommunication equipment, health-treatment equipment and tools, cooling-heating equipment, ventilation, furniture, lamps and chandeliers (1). After an earthquake, although the appearance of a hospital might not be damaged seriously, it would be unable to provide good service due to the damage to its nonstructural components. Owing to the importance of nonstructural components, it is vital and economic to examine the vulnerability of these components and to take some measures to retrofit them. Based on the issues proposed regarding the role of nonstructural components and their vulnerability, few studies have been conducted in this area. Earthquake regulations have paid little attention to this issue, not only in Iran but also in other countries (4). Previous experience has shown that even if the building is resistant against the earthquake, its nonstructural components have high potential to impose serious damage to residents or to interfere with the function of the building (2). Results of an Iranian study by Yeganeh et al. showed that the hospitals did not show proper resistance in times of crisis (5). Another study conducted in Tehran hospitals showed that hospitals had an average level concerning equipment, manpower, physical environment, related protocols and structure (6). Moreover, results of a study carried out on border hospitals in Kermanshah Province suggested that although these hospitals had adequate and desirable facilities and equipment, they were not prepared to face crises (7). According to the World Health Organization, following the Bam Earthquake in 2003, all three public and private hospitals of Bam were destroyed and other health centers were severely damaged (8). Since Kerman is considered a disaster-prone city in Iran (9), it is necessary to conduct further studies in this area so as to help the victims during and after the disaster. The present study aimed to assess the non-structural retrofitting status of Kerman hospitals.

\section{Material and Methods}

\subsection{Study design and setting}

The present study was of cross-sectional and descriptive type, and the statistical population consisted of Kerman teaching hospitals. The study was conducted in 2014.

\subsection{Instrument}

The research tool was a World Health Organization/Pan American Health Organization (WHO/PAHO) standard checklist of which validity and reliability was confirmed by the World Health Organization and Pan American Health Organization (10). In this study, the Persian version of the World Health Organization standard checklist validated by Ardalan et al. was used (11). This checklist assesses the vulnerability of hospitals in emergencies based on structural and non-structural factors and functional power. In this study, only the items related to non-structural components were used. This checklist was completed by the researcher in the second half of 2014 at four teaching hospitals of Kerman and in 9 separate sections including electrical systems, communication systems, water supply systems, fuel storage, medical gases (oxygen, nitrogen, etc.), heating and cooling systems and ventilation (HVAC), office and furniture, medical equipment for diagnosis and treatment and architectural elements.

\subsection{Statistical analysis}

Information was entered into the IBM(C) SPSS $\odot$ Statistics version 19 (IBM@ Corp., Armonk, NY, USA) and its numerical values were extracted. To analyze the data, descriptive statistics such as mean were used. In this assessment, low, moderate and high safety levels were given 1,2 and 3 points respectively. The items examined and assessed in this study included 8 items in electrical systems, 7 in communication systems, 5 in water supply systems, 4 in fuel storage, 7 in medical gases (oxygen, nitrogen, etc.), 7 in heating and cooling systems and ventilation (HVAC), 3 in office and furniture, 12 in medical equipment for diagnosis and treatment and 18 in architectural elements. These items were ranked from 1 for the lowest safety level to 3 for the highest safety level. Obtaining at least one-half of the total scores was considered low retrofitting level, the score between one-half and two-thirds represented average level, and score of more than two-thirds showed high level.

\subsection{Ethical considerations}

In order to comply with the ethical principles, the names of the hospitals were not mentioned in this study. Therefore, every hospital was given a number. We also took the permission of Kerman University of Medical Sciences and the affiliated hospitals to publish the study findings. 


\section{Results}

In four teaching hospitals affiliated to Kerman University of Medical Sciences, the non-structural retrofitting status was examined in nine separate sections including electrical systems, communication systems, water supply systems, fuel storage, medical gases (oxygen, nitrogen, etc.), heating and cooling systems and ventilation (HVAC), office and furniture, medical equipment for diagnosis and treatment and architectural elements. Based on the results obtained, on average, vital installations, including electrical systems $72 \%$, communication system $65 \%$, water supply system $65 \%$, fuel storage $66 \%$ and medical gases $62 \%$ were resistant. The results also respected for other non-structural components, (HVAC) 71\%, Office and furniture 81\%, medical equipment $63 \%$ and Architectural elements $74 \%$. Detailed results compare hospitals with each other, as shown in Table 1 and 2. As shown in these tables, the medical gas section and office, furniture and warehouse section had the lowest and highest resistance to natural disasters respectively. Generally, the non-structural retrofitting status was $50 \%$ (Low) in hospital No. 1, 81\% (High) in hospital No. 2, 67\% (Mid) in hospital No. 3 and 79\% (Mid) in hospital No. 4.

Table 1. Comparison of non-structural retrofitting of hospitals in natural disasters( vital installations)

\begin{tabular}{|l|l|l|l|l|l|}
\hline $\begin{array}{l}\text { Assessed Sectors (Vital } \\
\text { installations) }\end{array}$ & $\begin{array}{l}\text { Hospital } \\
\text { No. 1 }\end{array}$ & $\begin{array}{l}\text { Hospital } \\
\text { No. 2 }\end{array}$ & $\begin{array}{l}\text { Hospital } \\
\text { No. } 3\end{array}$ & $\begin{array}{l}\text { Hospital } \\
\text { No. } 4\end{array}$ & $\begin{array}{l}\text { Percent of ready } \\
\text { hospitals }\end{array}$ \\
\hline electrical system & 12.5 & 21.7 & 18.8 & 16.3 & $72 \%$ \\
\hline Retrofitting level & Low & High & High & Mid & N/A \\
\hline Communications system & 13 & 17 & 13 & 6 & $65 \%$ \\
\hline Retrofitting level & Low & High & High & Mid & N/A \\
\hline Water supply system & 6 & 12 & 9 & 12 & $65 \%$ \\
\hline Retrofitting level & Low & Mid & Low & Mid & N/A \\
\hline Fuel storage & 6 & 11 & 8.8 & 6 & $66 \%$ \\
\hline Retrofitting level & Low & High & Mid & Low & N/A \\
\hline Medical gases & 10 & 13.2 & 12.5 & 17 & $62 \%$ \\
\hline Retrofitting level & Low & Low & Low & Mid & N/A \\
\hline $\begin{array}{l}\text { Overview retrofitting Vital } \\
\text { installations }\end{array}$ & $50 \%$ & $80 \%$ & $66 \%$ & $70 \%$ & N/A \\
\hline Retrofitting level & Low & High & Mid & Mid & N/A \\
\hline
\end{tabular}

Table 2. Comparison of non-structural retrofitting of hospitals in natural disasters (Other non-structural components)

\begin{tabular}{|l|l|l|l|l|l|}
\hline $\begin{array}{l}\text { Assessed Sectors (Other non- } \\
\text { structural components) }\end{array}$ & $\begin{array}{l}\text { Hospital } \\
\text { No. 1 }\end{array}$ & $\begin{array}{l}\text { Hospital } \\
\text { No. 2 }\end{array}$ & $\begin{array}{l}\text { Hospital } \\
\text { No. 3 }\end{array}$ & $\begin{array}{l}\text { Hospital } \\
\text { No. 4 }\end{array}$ & $\begin{array}{l}\text { percent of ready } \\
\text { hospitals }\end{array}$ \\
\hline HVAC system & 12 & 20 & 9.9 & 18.5 & $71 \%$ \\
\hline Retrofitting level & Low & High & Low & High & N/A \\
\hline Office and furniture & 7.1 & 7.6 & 7.7 & 7 & $81 \%$ \\
\hline Retrofitting level & High & High & High & High & N/A \\
\hline Medical Equipment & 12.5 & 19.9 & 23.1 & 6.9 & $63 \%$ \\
\hline Retrofitting level & Low & Mid & Mid & Low & N/A \\
\hline Architectural elements & 21.7 & 46.3 & 36.8 & 46.3 & $74 \%$ \\
\hline Retrofitting level & Low & High & Mid & High & N/A \\
\hline $\begin{array}{l}\text { Overview retrofitting Vital } \\
\text { installations }\end{array}$ & $50 \%$ & $82 \%$ & $67 \%$ & $90 \%$ & N/A \\
\hline Retrofitting level & Low & High & Mid & High & N/A \\
\hline
\end{tabular}

\section{Discussion}

Concerning the retrofitting status, the present study showed that one of the hospitals had undesirable condition, one was relatively desirable and the others were in good conditions. A study conducted by Yeganeh et al. revealed that the non-structural retrofitting status of Tehran hospitals was unfavorable (5). Ardalan et al. assessed the safety of hospitals against disasters using self-assessment results of 224 hospitals; they reported that $54.5 \%$ of hospitals had low safety status and the rest had average status. None of the hospitals had high safety status (12). Evaluating 45 hospitals in the Caribbean showed that only $2 \%$ of hospitals were in safe condition, $80 \%$ were in average condition and $18 \%$ were in low safety condition (13). Zaboli et al. assessed the vulnerability of the organization and management of a selected military hospital in Tehran. They reported that the non-structural retrofitting status was 
average (14). In their study, Rabeian et al. reported that the preparedness of Tehran teaching hospitals against earthquake was average (15). In another study by Cliff et al. on preparedness level of American rural hospitals against disasters and risk perception and cooperation in rural areas, it was shown that these hospitals had an average preparedness level to deal with disasters (16). As mentioned above, the non-structural retrofitting status of Kerman teaching hospitals was moderate to high; it was in line with the results of other studies. However, it should be noted that, according to the weak chain theory, non-structural elements of a hospital are links of a chain, and weakness in any of them may cause the entire system to fail (17). Therefore, the average safety level of non-structural components cannot be an appropriate index of the vulnerability of a hospital. Thus, examining all non-structural factors and predicting some guidelines to improve their performance level will be closer to reality.

In the present study, it was observed that $72 \%$ of hospitals were in good condition in terms of electrical systems. Electrical systems must be designed in a way that cables at the main power station, specifically uninterruptible power supplies don't become damaged in disasters. For the passages leading to the vital parts of a hospital such as operating rooms and intensive care units, hospitals must have special light passages which must be available in times of crises. In the Northridge Earthquake in California (1994) which led to the evacuation of patients in 14 hospitals, the power outage was the main cause of hospital evacuation (18). In a study by Yeganeh et al., $43 \%$ of hospitals were in undesirable conditions in terms of electrical systems (5), while Seyedin et al. reported that $83 \%$ of hospitals had suitable electrical systems, and their results were in line with the results of the present study (19). Ardalan et al. showed that only $41.31 \%$ of hospitals were in good condition in terms of electrical systems, and the others were not in good condition; these results were inconsistent with the results of the present study (12). In their study, Seyedin et al. demonstrated that, lack of a clear information strategy and absence of an official system for registering crisis information at the local and provincial level was one of the main problems during a disaster (20). In the present study, the status of communication systems was average to high except for one hospital; these results were inconsistent with the results of studies conducted by Yeganeh et al. and Ardalan et al. $(5,12)$, but they were in line with the results of a study by Seyedin et al (19). Generally, communication systems must be designed in a way that they sustain minimal damage and continue working during disasters because the vital role of communication cannot be ignored in times of crises. Internal and external communication systems of hospitals shouldn't interfere with each other; satellite phones should also be used in emergencies.

In the present study, it was observed that $65 \%$ of hospitals were in relatively good condition concerning water supply systems, and none of the hospitals had ideal conditions in their water supply systems during the crisis. In a study by Yeganeh at al. (5), 57\% of the hospitals had desirable water supply systems; it was in line with the results of the present study. However, Seyedin et al. reported that $83 \%$ of the hospitals had desirable water supply systems, and their results were not in line with the results of the present study (19). The results of a study conducted by Ardalan et al. which showed that only $35.3 \%$ of the hospitals were in good condition were inconsistent with the results of this study (12). Concerning water supply systems, hospitals must estimate the amount of water they need every day based on their consumption needs, the number of beds and type of existing expertise. They must also provide the necessary tanks for emergencies. Hospitals should also predict water supply from other organizations such as Water and Sewage Organization and the Department of Environment. Concerning fuel storage, 66\% of hospitals were in relatively good condition; generally, the studied hospitals had average to low condition. In a study by Yeganeh at al., 57\% of the hospitals had desirable fuel storage and fuel distribution conditions. Ardalan et al. showed that $41.4 \%$ of the hospitals were in good condition, and their results were in line with the results of this study $(12,5)$. However, Seyedin et al. reported that $83 \%$ of the hospitals had desirable conditions, and their results were not in line with the results of the present study (19). Regarding fuel storage, it must be mentioned that most heating facilities work with natural gas which can be disconnected during disasters. Thus, predicting dual-fuel burners can be an appropriate measure to deal with gas cuts. If dual-fuel burners are used, safe and suitable places must be designed to store gasoline. Tanks must be protected, should not be damaged, and must remain available in times of crises. Another important point in the fuel supply system is to check fuel transfer pipes and fittings continuously because a defect in the fuel transfer system during disasters may lead to explosions and thus destruction of the hospital. Sixty-two percent of hospitals were in fairly good condition in terms of medical gases; the results were inconsistent with the results of studies conducted by Yeganeh et al., Seyedin et al. and Ardalan et al $(5,19,12)$. In all study hospitals, there were central medical gas distribution systems which may lose their effectiveness in times of crises. Thus, some portable tanks had been predicted for emergencies, but most of them were not protected appropriately and were dangerous. Concerning heating-cooling systems and ventilation, $71 \%$ of hospitals were in good condition; results were in line with the results of studies by Yeganeh and Seyedin (19, 5), but they were inconsistent with the results of a study conducted by Ardalan (12). It must be noted that heating-cooling 
systems consist of separate parts all of which are prone to damages during disasters. Thus, necessary steps must be taken to prevent the loss of these systems. Moreover, channels, air ducts, pipes and fittings must be visited periodically. Concerning office, warehouse and furniture, $81 \%$ of hospitals were in good condition; results were in line with the results of a study by Seyedin et al (19). Yeganeh et al. reported that $29 \%$ were in good condition, and Ardalan et al. showed that $31.1 \%$ were in good condition. These results were inconsistent with the results of the present study $(12,5)$. It must be noted that making use of standard computer tables can play an important role in protecting computers and their different parts. Sixty-three percent of studied hospitals were in relatively good condition in terms of medical equipment. In the medical equipment section, more measures must be taken for equipment, especially capital equipment. It is necessary that shelves with medical contents be screwed onto the walls to prevent them from falling. In a study by Arab et al on the preparedness level of hospitals affiliated to Iran University of Medical Sciences and Health Services against earthquake, it was shown than $47 \%$ of the study hospitals were in average condition concerning safety of equipment and dangerous materials (21). Ardalan et al. reported that $33.1 \%$ of the hospitals were in average condition; these results were not in line with the results of the present study (12).

Concerning architectural elements, $74 \%$ of hospitals were in desirable condition. Although architectural elements may not be directly involved in providing services, their damages can disrupt access to the hospital. In a study by Yeganeh et al., $86 \%$ of hospitals were in desirable condition, and Seyedin et al. reported that $94 \%$ of hospitals were in good condition $(19,5)$. Ardalan et al. reported that $37.6 \%$ of the hospitals were in good condition; these results were not in line with the results of the present study (12). Architectural components must have necessary strength so that they do not hinder access to different parts of the hospital. Components such as partitions, plaster works, fences, roof projections and false ceilings should all be fixed in a safe condition. Concerning fire protection systems, the hospitals had only fire extinguishers, and only one hospital had access to the fire box. Since fire engines may not be available to extinguish fires during a disaster, it is necessary to design high-pressure water posts for hospitals so as to prevent damage. Smoke and fire detectors were in unsatisfactory conditions; therefore, some measures must be taken to address this deficiency.

\section{Conclusions}

Iran is a developing country with imported technology; every year a huge amount of money is spent on importing and maintaining such technology. Moreover, Iran is considered a disaster-prone country in terms of both natural and man-made disasters. In sum, the overall assessment made of the non-structural retrofitting status of hospitals does not show favorable conditions, and most hospitals are in average state. Concerning high risks of the study hospitals against disasters, the practical implication of the study for the senior managers of Kerman Province and medical universities is to take some measures to retrofit these buildings and to reduce the risk of vulnerability. For nonstructural components in vital installations, higher performance levels require a closer approach to assess the seismic vulnerability and to develop appropriate retrofitting strategies. Using the experiences of other countries in dealing with crises and disasters can greatly help to standardize non-structural components. For a hospital to continue uninterruptedly in times of crisis, there are some guidelines and standards that hospitals should observe as much as possible. These guidelines may cover the simplest issues to the technical and complex ones; their ultimate goal is to increase hospital preparedness against crisis as well as to prevent serious damage to the hospital. Hospital preparedness is not a simple commitment in any hospital. In preparation, a clear performance framework and a new and specific program which encompasses details of internal and external responding systems is essential. Conducting additional research in the field of non-structural retrofitting on teaching and non-teaching hospitals of Iran, through random sampling, can be an appropriate direction for future research on this topic.

\section{Acknowledgments:}

We kindly thank the authorities of Kerman University of Medical Sciences and all affiliated hospitals who cooperated in different stages of the study. Additionally this study is a part of a M.Sc. thesis in health care management which was sponsored by Environmental Health Engineering Research Center of Kerman University of Medical Sciences.

\section{Conflict of Interest:}

There is no conflict of interest to be declared.

\section{Authors' contributions:}

All authors contributed to this project and article equally. All authors read and approved the final manuscript. 


\section{References:}

1) Hosseyni M, Montazer Al Gaaem S, Aminaee CA. Practical Guideline to reduce damage non-structural elements of buildings in earthquake. Prevention and crisis management organization in Tehran, TehranIran. 2008.

2) Khankeh Hamidreza. Disaster preparedness in hospitals. Social Welfare and Rehabilitation Sciences University, Tehran-Iran 2012.

3) Jahangiri Katayoun. Principles of Disaster Management. Iran Crescent Scientific-Practical Institute of Higher Education, Tehran-Iran. 2011.

4) Vatar M Gh. Non-structural seismic vulnerability of hospitals and essential components of their development. Fourth International Conference on Earthquake Engineering and Seismology (SEE4). Tehran- Iran. 2003.

5) Yeganeh SH, Asadi M, Seyyedin SH, Maher A. Measure the quantity and quality of equipment and nonstructural vulnerability of General hospitals during an earthquake in Tehran. Journal of rescue. 2011; 3(12).

6) Hojat M, Sirati Nir M, Khaghanizade M, Karimi Zarchi M. Investigation of Preparedness Rate of Tehran's Hospitals encounters Unexpected Events. Daneshvar Journal. 2008; 15(74): 1-10.

7) Nasiripour A A, Raisee P, Mahboubi M. Study of Preparedness Rate of Marginal Hospitals encounters Crises. Health Management Journal. 2007; 10(28): 41-8.

8) World Health Organization. The Government of the Islamic Republic of Iran and WHO joint project for: "Reconstruction of health services in Bam". Part I Background and immediate response. 2007.

9) Hasanzadeh R, Abbasnejad A, Alavi A, Sharifi E. Analysis of seismic risk in the city of Kerman with emphasis on GIS in sub-zones of primary grade 2. Earth Sciences. 2011; 21(81): 23-30.

10) Hospital Safety Index. Evaluation Forms for Safe Hospitals. Pan American Health Organization, Washington DC. 2008.

11) Ardalan A, Shariati M, Kandi M, Sadeghi Ghotb-Abadi F. Disaster Risk Assessment in Primary Health Care Facilities. Ministry of Health \& Medical Education, Tehran. 2011.

12) Ardalan A, Kandi M, Talebian MT, Khankeh H, Masoumi G, Mohammadi R, et al. Hospitals Safety from Disasters in I.R.Iran: The Results from Assessment of 224 Hospitals. PLoS Curr. 2014; 6. doi: 10.1371/currents.dis.8297b528bd45975bc6291804747ee5db. PMID: 24596661, PMCID: PMC3938570.

13) Jagnarine SH. Safe hospitals in Caribbean. Pan American Health Organization. 2014. Available From:

14) http://www.jm.undp.org/content/dam/jamaica/docs/environment/SeismicForum2014/ShaliniJangnarineSafe HospitalsProgramme.pdf. Accessed: 07 February 2014.

15) Zaboli RA, Toufighi Sh, Seyyedin Sh, Malmoon Z, Hosseini Shokuh M. Organizational vulnerability and management of clinical departments against crisis. Iranian Journal of Critical Care Nursing. 2009; 2(3): 99103.

16) Rabeian M, Hosseini H, Radabadi M, Taheri Mirghaed M, Bakhtiari M. Evaluation Of Effective Factors On The Rate Of Preparedness Of Tehran University Of Medical Sciences' Selected Hospitals In Dealing With Earthquake. Health Fertility \& Sterility journal. 2013; 7(3): 251-61.

17) Cliff BJ, Morlock L, Curtis AB. Is there an association between risk perception and disaster preparedness in rural us hospitals? Prehosp Disaster Med. 2009; 24(6): 512-7. doi: 10.1017/S1049023X00007433. PMID: 20301069.

18) Yeganeh SH. Fundamental of Search \& Rescue. Red Crescent Society of Ghom Province. 2004; 96495934-2-X.

19) Schultz CH, Koenig KL, Lewis RJ. Implications of Hospital Evacuation after the Northridge, California, Earthquake. N Engl J Med. 2003; 348(14): 1349-55. doi: 10.1056/NEJMsa021807. PMID: 12672863.

20) Seyedin H, Abasi Dolat Abadi Z, Sorani M, Naghdi S, Rajabfard Mazraeno F. Vulnerability assessment of general hospitals of Tehran University of Medical Sciences. Health Promotion Management. 2014; 3(2(10)): 65-72.

21) Seyedin H, Sajjadi H, Zaboli R. The Status of the Emergency Information and Communication System in Iran's Health Sector. Health Information Management. 2012; 9(1): 55-63.

22) Hosseini Shokouh M, Arab M, Rahimi A, Rashidian A, Sadr Momtaz N. Preparedness of the Iran University of Medical Sciences hospitals against earthquake. Journal of school of public Health and institute of public health research. 2009; 6(3-4): 61-77. 